\title{
Strategies that facilitate or counter eavesdropping on vocal interactions in songbirds
}

\author{
TORBEN DABELSTEEN \\ Animal Behaviour Group and Centre for Sound Communication, Biological Institute \\ University of Copenhagen, Tagensvej 16, DK-2200 Copenhagen N, Denmark
}

Manuscript received on January 15, 2004; accepted for publication on February 5, 2004.

\begin{abstract}
Most territorial songbirds live in communication networks where eavesdropping on vocal interactions may constitute an important option for gathering information regarding the relative dominance, condition and quality of individuals being eavesdropped upon. The relatively low costs and risks of eavesdropping, together with the obvious advantages of gaining such comparative information about other individuals, predict eavesdropping to be a widespread phenomenon even though it is not necessarily advantageous for the participants to be eavesdropped upon. Special eavesdropper strategies that facilitate eavesdropping (how best to eavesdrop) may therefore have evolved together with strategies for interacting that either co-facilitate (public signaling) or counter eavesdropping directly (private signaling) or indirectly by preventing any subsequent negative consequences of being eavesdropped upon (anonymity). This paper reviews the predictions for the strategies and also gives examples supporting their use by territorial songbirds in connection with vocal interactions.
\end{abstract}

Key words: communication networks, eavesdropping strategies, vocal interactions.

\section{INTRODUCTION}

The majority of animals have signals that are relatively long-ranging and can be perceived by several conspecific individuals at the same time in many situations. This is true also for those songbirds that maintain distance from each other by defending large territories. Like most animals, territorial songbirds can be said to be members of communication networks where each individual has several options for gathering information about each other (Dabelsteen 1992, McGregor 1993). A bird may for instance gain information about other individuals by acting as a simple receiver, which receives signals from one individual at a time. It may also be in a location where it can receive the signals

E-mail: tdabelsteen@zi.ku.dk of both of two interacting individuals, for instance two males engaged in a song duel. By listening to how the two individuals use their signals towards each other, the listener may gain comparative information about the interacting individuals. A female songbird that is listening to how two singing males match or overlap each others' songs during a song duel, may for instance gain information regarding the relative dominance, condition or quality of the males. Since such comparative information results from how the two males interact, it cannot easily be gained by a simple reception of songs from one male at a time. Extracting comparative information from a signaling interaction is therefore a special process referred to as eavesdropping (McGregor and Dabelsteen 1996). Field experiments 
have now demonstrated that songbirds of both sexes do have the ability to eavesdrop on singing interactions and utilize information about relative dominance gathered by eavesdropping in later decision making. Male eavesdroppers may utilize this information in deciding how to respond to later intrusions from one of the eavesdropped males (e.g. Peake et al. 2001, 2002), and female eavesdroppers may utilize the information to decide whether they should pay one of the eavesdropped males a visit in preparation for extra-pair copulations (Otter et al. 1999, Mennill et al. 2002).

Undoubtedly, eavesdropping is a low cost and low risk alternative to, for instance, gathering the same comparative information through direct interactions with the individuals eavesdropped upon. This, together with the obvious advantages of gaining comparative information about other individuals, predicts eavesdropping to be a widespread phenomenon (McGregor and Dabelsteen 1996), which may even be facilitated by specially evolved eavesdropper strategies. Sometimes eavesdropping may even benefit the individuals eavesdropped upon suggesting the evolution of strategies that expose these individuals to eavesdropping. However, most often eavesdropping seems disadvantageous to at least one of the interactants, e.g. the looser of an agonistic interaction, suggesting the evolution of strategies that may counter eavesdropping and the potential successive negative consequences of being eavesdropped. Based mainly on the results of sound transmission experiments, this paper will briefly review the predictions for four strategies that facilitate or counter eavesdropping on vocal interactions, but see Dabelsteen (2004) for a more detailed review.

\section{FACILITATING EAVESDROPPING}

\section{How Best to EAVESDROP}

An eavesdropper should of course be able to receive the sound signals of both interactants simultaneously and from a position that gives a correct idea of the timing of the interacting individuals' vocalizations when the timing is an important cue. A good example of this is the many species of songbirds where an overlapping or alternating singing pattern is an important feature of dominance (e.g. Dabelsteen et al. 1997). One way of making eavesdropping on a song duel effective would therefore be to approach the singing males to a position equidistant from both of them where the songs of both males can be effectively extracted from the background noise. In a deciduous forest an eavesdropper might also move up to high perches above the undergrowth because this significantly improves the conditions for most kinds of information gathering, including ranging, at least before the trees get leaves (e.g. Dabelsteen et al. 1993, Holland et al. 1998, 2001). Sound signals generally seem to degrade less and in a more predictable way with distance, when they propagate through a forest at heights well above the ground level (see Mathevon et al. 1996 and Nemeth et al. 2001). Perching as an alternative to approaching may save energy and also counter detection by the bird being eavesdropped upon, when this is desirable. A territory owner that is eavesdropping on a song duel close to its territory during, for instance, the dawn chorus might even preserve the ability to detect important interactions that start in other directions. The behavior of eavesdroppers during eavesdropping has, as far as I know, not yet been quantified. However, there is anecdotal evidence that eavesdroppers may behave as predicted with respect to perching or positioning themselves relative to the interactants.

\section{Public Signaling}

Public signals are aimed at a wide audience and are long-ranging by definition. Public signals should therefore be relatively resistant to sound degradation during transmission in the actual habitat and they should mainly be used from positions and times of the day that facilitate transmission and reception of the signals. A good example is the full song of songbirds, which usually has an advertising function and is used both during solo singing and in singing interactions where the interactants unavoidably expose themselves to eavesdropping. Relative to other song 
types, full song always transmits at relatively long distance for several reasons: it is usually sung from high posts, it often includes more or less omnidirectional sounds, and the sounds are relatively loud, low frequency and narrowband (e.g. Dabelsteen et al. 1993, Holland et al. 1998, Larsen and Dabelsteen 1990; Fig. 1). In some species the male may move the head from side to side during solo singing, probably to compensate for possessing less omnidirectional sounds (Brumm and Todt 2003). Whether birds increase the features of song that make the singing public when they switch from solo singing to interactive singing to facilitate eavesdropping on their interaction is still unknown. However, there is evidence that some birds may increase the output level in this situation (Brumm and Todt 2004).

\section{COUNTERING EAVESDROPPING}

\section{Private Signaling}

Private signaling is in effect the opposite of public signaling. Any choice of signal type and signaling behavior and conditions that constrain transmission and reception of signals in the actual habitat may therefore be part of a privatizing strategy. A good example is the so-called quiet singing and calling that are used by many songbirds during close-range escalated agonistic and sexual interactions where the birds are vulnerable to eavesdropping for different reasons (Dabelsteen et al. 1998, Titus 1998, Dabelsteen 2004). The vocalizations are usually accompanied by posturing and undetectable at distances longer than 15-20 m, or even at shorter distances in some directions because of their directional spreading (Larsen and Dabelsteen 1990). Quiet singing and calling is often used from relatively low positions and at times of the day where the level of the background noise is high (e.g. Dabelsteen et al. 1998, Balsby et al. 2003). Their relatively high frequencies and high degree of modulation, together with their broadband nature, make them sensitive to degradation factors (e.g. Dabelsteen et al. 1993, Balsby and Dabelsteen 2003).

\section{ANONYMITY}

A prerequisite for utilization of the comparative information obtained by eavesdropping is that the interactants can be recognized by the eavesdropper. Any step that would help making an interactant anonymous would therefore counter both immediate and later negative consequences of being eavesdropped, should the use of private signals be insufficient to avoid eavesdropping per se. In many songbirds individuals may somehow be identified by their song repertoire and very large repertoires should interfere with repertoire-based recognition for different reasons (e.g. Stoddard 1996). One way of shifting to anonymity would therefore be to increase the variation of the song output, for instance by increasing the song repertoire and the time between each repetition of the same song. The idea of anonymity is novel (Dabelsteen 2004), but quiet singing seems to be a good candidate also for this strategy, because quiet singing is much more variable than full singing in some species (Fléron 2003, Dabelsteen 2004). How important anonymity is in an eavesdropping context and whether this strategy also is an option for other signaling modalities has yet to be investigated.

\section{ACKNOWLEDGMENTS}

Thanks to the many different people with whom I have discussed ideas presented in this review. More recently, Thorsten Balsby, Sandra Blumenrath, Safi Darden, Peter McGregor, Nicolas Mathevon, Ricardo Matos, Tom Peake and Angelika Poesel gave especially valuable input. Centre for Sound Communication and the Danish National Science Foundation has funded most of my research on communication networks.

\section{RESUMO}

A maioria dos pássaros territoriais vive em redes de comunicação onde a espiada das interações vocais pode representar uma maneira importante de obter informações sobre as relações de dominância e as condições dos indivíduos espiados. Os custos e riscos relativamente baixos 

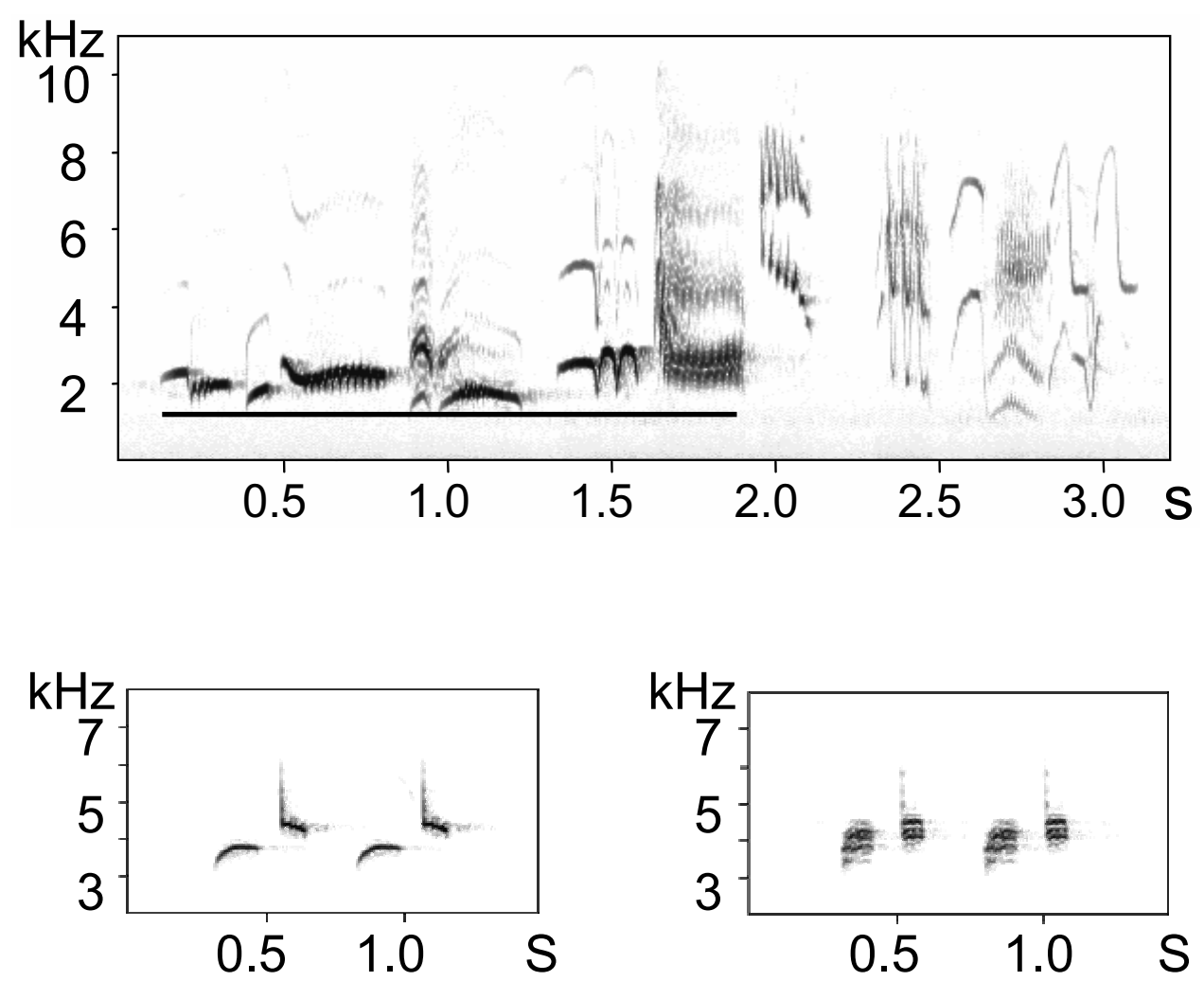

Fig. 1 - Predictions for public signaling. Sound transmission experiments predict that public signaling should include the use of high SPL, low frequency, narrowband and unmodulated signals, emitted above the ground level, possibly from high perches. In Blackbirds Turdus merula (above), whistle sounds (underlined) transmit better than twitter sounds. In Great Tits Parus major (below), pure notes (left) transmit better than buzzes (right).

de tal espionagem, junto com as vantagens óbvias de obter tais informações comparativas sobre outros indivíduos, indicam que deve ser um comportamento bem difundido, mesmo que não seja necessariamente vantajoso para os participantes que são espiados. Estratégias especiais facilitando a interceptação (como melhor espiar) podem então ter evoluído junto com estratégias de interações que ou facilitam reciprocamente (sinalização pública) ou contrariam a espionagem diretamente (sinalização privada) ou indiretamente evitando as conseqüências negativas de ter sido espiado (anonimato). Este artigo revisa as predições sobre essas estratégias e também dá exemplos confirmando seu uso por pássaros territoriais em relação a suas interações vocais.

Palavras-chave: redes de comunicação, estratégias de interceptação, interações vocais.

\section{REFERENCES}

Balsby TJS and Dabelsteen T. 2003. Degradation of Whitethroat vocalizations: implications for song flight and communication network activities. Behaviour 140: 695-719.

Balsby TJS, Dabelsteen T and Pedersen SB. 2003. Male singing behaviour and female presence in the territory in Whitethroats Sylvia communis. Acta Ethologica 5: 81-88.

Brumm H And TodT D. 2003. Facing the rival: directional singing behaviour in nightingales. Behaviour 140: 43-53.

Brumm H AND TodT D. 2004. Male-male vocal interactions and adjustment of song amplitude in a territorial bird. Anim Behav 67: 281-286.

DABELSTEEN T. 1992. Interactive playback: a finely tuned response. In: McGregor PK. (Ed), Playback 
and Studies of Animal Communication. New York: Plenum Press, p. 92-109.

Dabelsteen T. 2004. Public, private or anonymous? Facilitating and countering eavesdropping. In: McGregor PK. (Ed), Animal Communication Networks. Cambridge: Cambridge University Press (in press).

Dabelsteen T, Larsen ON and Pedersen SB. 1993. Habitat-induced degradation of sound signals: Quantifying the effects of communication sounds and bird location on blur ratio, excess attenuation, and signalto-noise ratio in Blackbird song. J Acoust Soc Am 93: 2206-2220.

Dabelsteen T, McGregor PK, Holland J, Tobias J ANd Pedersen SB. 1997. The signal value of overlapping singing in male Robins (Erithacus rubecula). Anim Behav 53: 249-256.

Dabelsteen T, McGregor PK, Lampe HM, Langmore NE and Holland J. 1998. Quiet singing in song birds: an overlooked phenomenon. Bioacoustics 9: 89-105.

FLÉron GMW. 2003. An analysis and comparison of the aggressive twitter with the twitter of the full song in the Blackbird (Turdus merula). Unpubl. Ms. Diss., University of Copenhagen, 87pp.

Holland J, Dabelsteen T, Pedersen SB and Larsen ON. 1998. Degradation of Wren Troglodytes troglodytes song: implications for information transfer and ranging. J Acoust Soc Am 103: 2154-2166.

Holland J, Dabelsteen T, Pedersen SB and Paris AL. 2001. Potential ranging cues contained within the energetic pauses of transmitted Wren song. Bioacoustics 12: 3-20.

LARSEN ON AND Dabelsteen T. 1990. Directionality of Blackbird vocalization. Implications for vocal communication and its further study. Ornis Scand 21: 37-45.

Mathevon N, Aubin T and Dabelsteen T. 1996. Song degradation during propagation: importance of song post for the Wren Troglodytes troglodytes. Ethology 102: 397-412.
McGregor PK. 1993. Signalling in territorial systems: a context for individual identification, ranging and eavesdropping. Phil Trans R Soc Lond B340: 237244.

McGregor PK and Dabelsteen T. 1996. Communication networks. In: Kroodsma DE AND MilleR E. (Eds), Ecology and Evolution of Acoustic Communication in Birds. Ithaca, NY: Cornell University Press, p. 409-425.

Mennill DJ, Ratcliffe LM and Boag PT. 2002. Female eavesdropping on male song contests in songbirds. Science 296: 873 .

Nemeth E, Winkler H and Dabelsteen T. 2001. Differential degradation of antbird songs in a Neotropical rainforest: Adaptation to perch height? J Acoust Soc Am 110: 3263-3274

Otter KA, McGregor PK, Terry AMr, Burford FRL, Peake TM and Dabelsteen T. 1999. Do female Great Tits Parus major assess males by eavesdropping? A field study using interactive song playback. Proc R Soc Lond B266: 1305-1309.

Peake TM, Terry AMr, McGregor PK and DabelSTEEN T. 2001. Male Great Tits eavesdrop on simulated male-to-male vocal interactions. Proc R Soc Lond B268: 1183-1187.

Peake TM, Terry AMr, McGregor PK and DabelSTEEN T. 2002. Do Great Tits assess rivals by combining direct experience with information gathered by eavesdropping? Proc R Soc Lond B269: 19251929.

STODDARD PK. 1996. Vocal recognition of neighbours by territorial passerines. In: Kroodsma DE AND Miller E. (Eds), Ecology and Evolution of Acoustic Communication in Birds. Ithaca, NY: Cornell University Press, p. 356-374.

Titus RC. 1998. Short-range and long-range songs: use of two acoustically distinct song classes by Darkeyed Juncos. Auk 115: 386-393. 